\title{
Elecciones y partidos en México: 1988-1990
}

$\mathrm{E}$

n más de una ocasión, el sistema político mexicano ha sido utilizado como ejemplo para la elaboración de tipologías sobre regímenes autoritarios. El carácter no competitivo de nuestro subsistema electoral se ha enfatizado frecuentemente. ${ }^{1}$ Hasta el verano de 1988, las elecciones habían sido un fenómeno regular y altamente predecible. Formalmente, existía competencia entre los partidos políticos aun cuando, en realidad, la competitividad era nula. ${ }^{2}$

${ }^{1}$ Véase L. Valdés, "Tres tipologías de los setenta: el sistema de partidos en México, sus cambios recientes", en Sociologica, revista de la UAM-A, núm. 11, septiembre-diciembre de 1989.

${ }^{2}$ Giovanni Sartori propone una diferenciación
Por tal motivo, si nos preguntamos qué nos dejaron las elecciones presidenciales más competidas de la historia reciente, una de las posibles respuestas nos conduce al terreno de la competitividad político-electoral. El desgajamiento del partido hegemónico, los cambios en las pautas de comportamiento electoral de los ciudadanos, las evidencias del surgimiento de una nueva cultura política, entre otros, son temas sobre los cuales estamos obligados a reflexionar. No obs-

entre competencia y competitividad. La primera atiende a las reglas del juego; la segunda describe el estado real del mismo. G. Sartori, Partidos y sistemas de partidos, Alianza Universidad, Madrid, 1980 , p. 260. 
tante, las pretensiones de este trabajo son más modestas; intenta tan sólo mostrar las transformaciones que hemos vivido en el terreno de la competitividad electoral durante y después de las elecciones de 1988.

Un buen indicador para medir niveles de competitividad electoral se encuentra en la comparación de la propor- ción de votos que obtienen los partidos políticos. Se puede decir que una elección es competida si los candidatos perdedores obtienen una elevada proporción de votos con respecto a los que alcanza el ganador. Si, por el contrario, los derrotados alcanzan una reducida proporción con respecto a los votos abtenidos por el triunfador, se considera que no hubo competitividad.

El cuadro 1 contiene algunos indicadores para el caso mexicano. Compara los votos alcanzados por el PAN, FDN y PMS con los obtenidos por el PRI. Como se puede ver, a partir de la reforma politica de 1977, el desempeño competitivo de los partidos evolucionó lentamente hasta las elecciones de 1985 . En las de 1988 los niveles de competitividad se elevaron significativamente en virtud de los resultados obtenidos por el PAN y por los partidos que integraron el Frente Democrático Nacional. ${ }^{3}$ El PAN obtuvo más votos que el PRI en 32 distritos y el FDN, en 77; esto significa que el partido antes hegemónico fue derrotado en $36 \%$ de los distritos. En otros 54 distritos (que representan $18 \%$ del total) los opositores alcanzaron más de $80 \%$ de la votación obtenida por el PRI.

¿A qué se debe este cambio tan significativo en la competencia electoral

${ }^{3}$ Para este análisis se utilizan los datos oficiales, a pesar de las sospechas que se abrigan sobre ellos, simple y sencillamente porque no existen otros.

Cuadro 1

INDICADORES DE COMPETITIVIDAD ELECTORAL

PARTIDO ACCIÓN NACIÓNAL

Proporción de votos

$\begin{array}{llll}1979 & 1982 & 1985 & 1988\end{array}$

con respecto a la

votación del PRI

(Diputados M R)

$15.47 \%$

$25.30 \%$

$24.05 \%$

$35.16 \%$

Distritos

PAN/PRI 1

1 P,AN/PRI .80

.80 PAN/PRI .60

$.60 \mathrm{PAN} / \mathrm{PRI} .40$

.40 PAN/PRI .10

PAN/PRI . 10

Total

4
7
4
27
114
144
300

1
9
33
73
84
100
300

9
9
20
67
99
96
300


Partido Popúlar Socialista

Partido Auténtico de la Revolución Mexicana

Partido Socialista de los Trabajadores (Después llamado PFCRN)

Proporción de votos

$\begin{array}{llll}1979 & 1982 & 1985 & 1988\end{array}$

con respecto a la

votación del PRI

(Diputados M R)

$9.34 \%$

$7.28 \%$

$9.37 \%$

$48.22 \%$

\section{Distritos}

FDN/PRI 1

1 FDN/PRI 80

$.80 \mathrm{FDN} / \mathrm{PRI} .60$

$.60 \mathrm{FDN} / \mathrm{PRI} .40$

.40 FDN/PRI .10

FDN/PRI .10

Total

$\begin{array}{rr}0 & \\ 1 & \\ 2 & \\ 3 & \\ 122 & 88 \\ 172 & 209 \\ 300 & 300\end{array}$

0
1
1
1
88
209
300

77

27

20

35

84

57

300

Partido Comunista Mexicano (1979)

Partido Socialista Unificado de México (1982 y 1985)

Partido Mexicano de los Trabajadores (1985)

Partido Mexicano Socialista (1988)

Proporción de votos

$$
\begin{array}{llll}
1979 & 1982 & 1985 & 1988
\end{array}
$$

con respecto a la

votación del PRI

(Diputados M R)

$\begin{array}{llll}7.10 \% & 6.30 \% & 7.35 \% & 8.70 \%\end{array}$

Distritos

PMS/PRI 1

1 PMS/PRI .80

.80 PMS/PRI .60

.60 PMS/PRI .40

.40 PMS/PRI .10

PMS/PRI . 10

Total

$\begin{array}{rr}0 & 0 \\ 0 & 1 \\ 0 & 0 \\ 0 & 0 \\ 100 & 84 \\ 200 & 215 \\ 300 & 300\end{array}$

$\begin{array}{rr}0 & 0 \\ 0 & 0 \\ 1 & 4 \\ 2 & 12 \\ 91 & 90 \\ 206 & 194 \\ 300 & 300\end{array}$

Para el caso del FDN se sumaron los votos obtenidos por los tres partidos que lo conformaron: PPS, PARM y PST (PFCRN, en 1988).

Para el caso de pMs se consideraron los votos obtenidos por los partidos que le dieron origen al fusionarse: PS ( $y$ su antecedente PCM) y PMr.

Fuente: Comisión Federal Electoral. 
mexicana? En el terreno de las reglas del juego -en sentido estricto, de la competencia-es necesario reconocer que desde la reforma lopezportillista las cosas venían cambiando. El registro legal de nuevos partidos, la relativa apertura de la Cámara de Diputados y el acceso, en tiempos de campaña, a los medios de comunicación electrónicos, fueron algunos de los elementos que dieron la pauta a los cambios en la competencia. Más partidos, con más espacios políticos por llenar y mejor pertrechados para las contiendas comiciales, son parte del saldo de la reforma política.

En el campo del juego -de la competitividad-en 1988 se sumaron otros factores. Evidentemente, Acción Nacional capitalizó las facilidades que la Ley Federal sobre Organismos y Procesos Electorales (LFOPPE) ofrecía a los partidos opositores y logró captar la participación y el descontento de algunos grupos empresariales. Aparecía así como un contendiente más fuerte que seis años atrás. El PRI sufrió una nueva fractura de grandes dimensiones y los partidos que conformaron el FDN -PPS, PARM y PSTse beneficiaron electoralmente de tal circunstancia. La izquierda avanzó en el camino de su unidad, pero la dinámica del enfrentamiento entre priistas, ex priistas y panistas la marginó rápidamente. Lo mismo sucedió con los partidos de extrema derecha (PDM) y extrema izquierda (PRT); la marginación de estos últimos fue tal que, al no lograr el mínimo de votación exigido por la ley $(1.5 \%$ del total), perdieron su registro legal.

Ante la profundización de la competitividad electoral en 1988, surge la pregunta: ¿habrá sido un fenómeno pasajero? Para intentar responder a tal interrogante veamos qué ha sucedido en las elecciones locales que se realizaron posteriormente, los efectos de la nueva si- tuación sobre las recientes modificaciones a la legislación electoral y sus implicaciones en la conformación de los principales actores de la competencia: los partidos políticos.

\section{LA COMPETITIVIDAD EN LAS ELECCIONES LOCALES}

La competitividad electoral, en México, ha sido un fenómeno con fuerte carga regional. Tómese por ejemplo el caso de las primeras elecciones federales posteriores a la reforma política. El único contendiente que pudo presentar un perfil más o menos competitivo fue Acción Nacional; sin embargo, al observar la ubicación distrital de sus triunfos se evidencia su carácter regional. Las cuatro victorias distritales del PAN fueron norteñas: dos en Nuevo León, una en Coahuila y una más en Sonora. Eso no fue todo. De los siete distritos en que Acción Nacional obtuvo $80 \%$ de los votos ganados por el PRI, cinco correspondieron a Nuevo León, uno a Coahuila y tan sólo uno a la zona centro del país: Guanajuato.

En el verano de 1988 también se mostró el perfil claramente regionalizado de la competitividad. En el cuadro 2 se encuentra el cálculo de un sencillo indice de competitividad. Se utilizan los distritos en los cuales el PAN y el FDN alcanzaron votaciones superiores al $80 \%$ de los votos captados por el PRI. Como se observa, eso sucedió en 163 de los 300 distritos federales. El índice -que no es más que un simple porcentaje- se sitúa en $54.3 \%$, muy por arriba del nivel alcanzado en elecciones anteriores ( $4 \%$ en $1979,3.6 \%$ en 1982 y $7 \%$ en 1985 ), pero con evidentes modificaciones regionales. De hecho, en ocho entidades (las marcadas con asterisco en el cuadro 2) se 


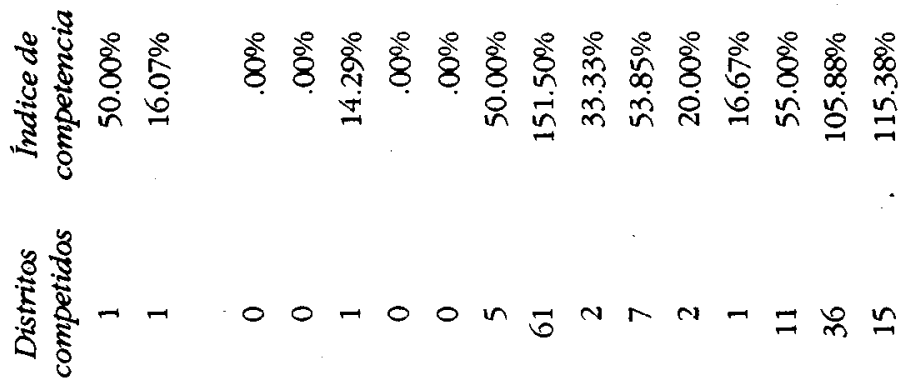

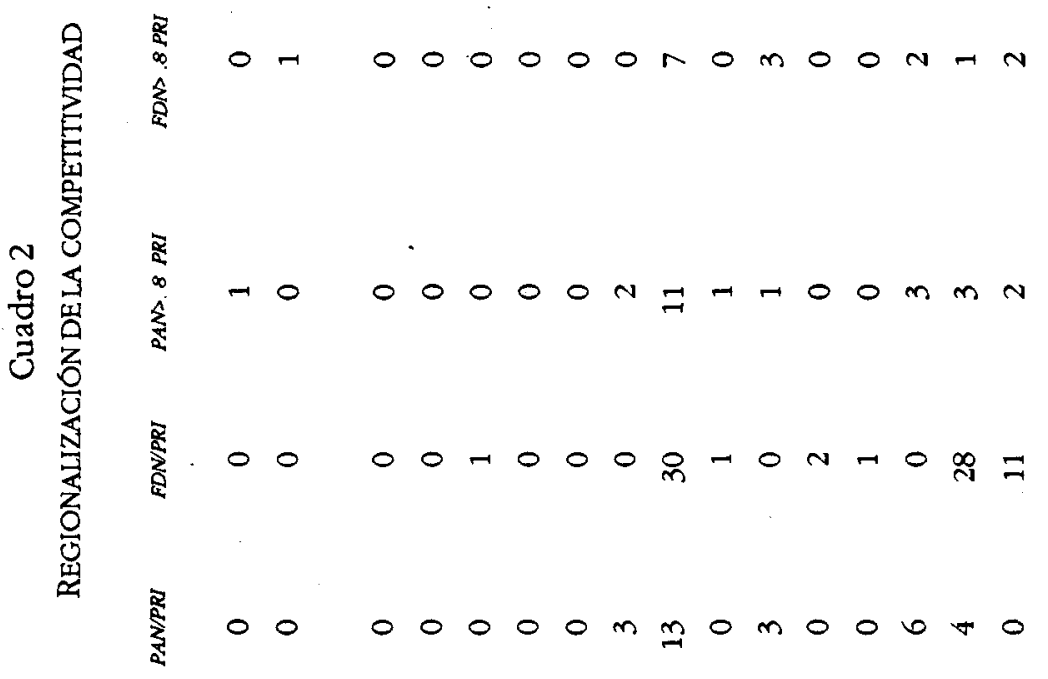

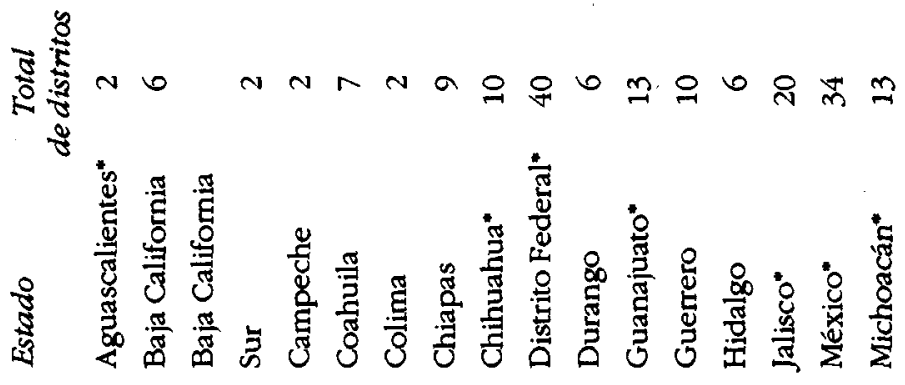




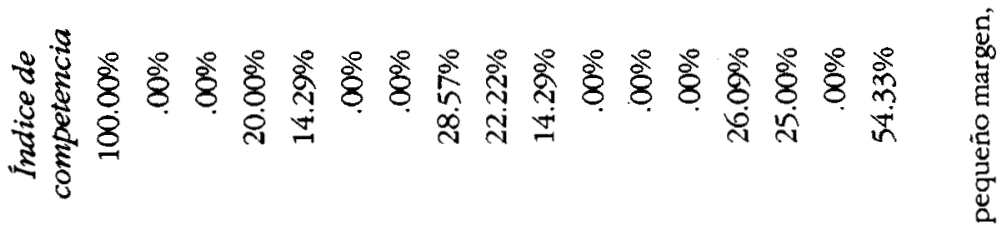

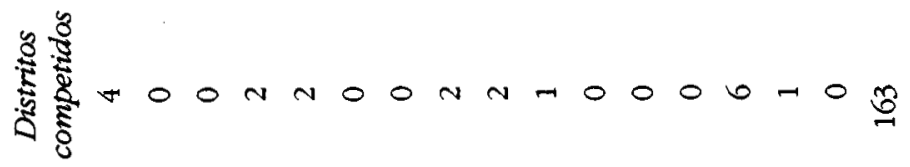

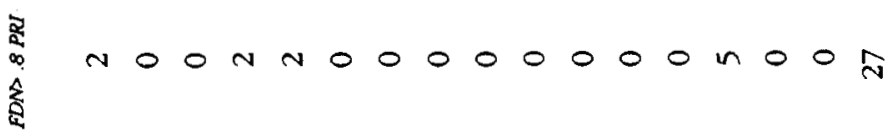

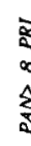

No00000000000700k

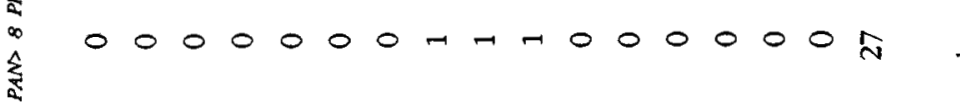

$\sum_{1}^{\infty} 000000007-7000000 N$

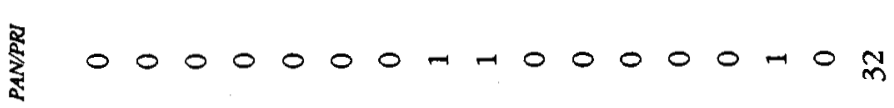

$\frac{2}{8}$

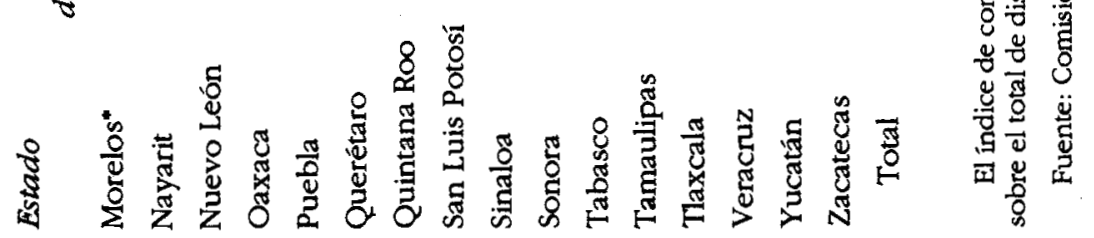


puede hablar de competencia y en algunos casos ésta llegó a niveles extraordinariamente elevados: Distrito Federal, Michoacán, Estado de México y Morelos.

El índice utilizado tiene una ventaja: exhibe cómo la cerrada competencia por la presidencia de la república arrastró a la votación recibida por los candidatos a diputados por mayoría. Contiene también la excepción que confirma la regla: en Baja California, Cuauhtémoc Cárdenas ganó por escaso margen y el hecho no se tradujo en alta competitividad en la elección de diputados.

El diagnóstico de la competitividad en los comicios federales de diputados ofrece pistas para el análisis de ese-mismo fenómeno en elecciones locales, y a la vez permite diferenciar ambos tipos de contiendas y detectar la dinámica propia de las elecciones de carácter regional.

Entre julio y diciembre de 1988 se celebraron elecciones municipales en Campeche, San Luis Potosi, Tlaxcala, Veracruz y Zacatecas, y municipales y para renovar el Congreso en Chiapas, Guanajuato, Jalisco, Nuevo León y Tabasco. De acuerdo con los resultados obtenidos en la elección del 6 de julio, se esperaba que los más altos niveles de competitividad se dieran en Guanajuato y Jalisco, pero no fue así: Tabasco dio la sorpresa. En Jalisco, se renovaron ayuntamientos, Congreso y gobernador, pero Acción Nacional -el principal contendiente- no pudo consolidar lo logrado en la elección federal. Su candidato a la gubernatura alcanzó 232317 votos, quedando muy por debajo del priista, quien logró 518477 . Se preveía el triunfo del PAN en Guadalajara; al parecer, el elevado nivel de abstención lo impidió. En Guanajuato, al parecer, el fracaso del PDM en los comicios federales impactó la competitividad. En este caso, la abstención resultó también muy ele- vada y el PRI logró una holgada victoria, salvo en la ciudad de León, donde triunfó el PAN.

El caso de Tabasco atrajo la atención desde que se calificó la elección federal. Uno de los presuntos diputados por ese estado anunció su decisión de cambiar de partido: abandonó el PRI y se incorporó a la bancada del FDN. A la vez, un destacado político local (Manuel López Obrador) hizo pública su decisión de participar como candidato a la gubernatura por la corriente cardenista con el respaldo del PMS y algunos partidos del FDN. Ganó el candidato prísta. López Obrador obtuvo una votación nada despreciable: 55 957, sobre todo si se la compara con los 11296 que alcanzó el conjunto de la oposición seis años antes. Los conflictos que se registraron fueron producto de los muy elevados niveles de competencia electoral, nunca antes registrados en esa entidad altamente priista.

En lo que va del actual sexenio se efectuaron elecciones en julio de 1989 en Baja California para elegir gobernador, Congreso y presidentes municipales; en Campeche, Michoacán, Zacatecas (julio), Veracruz (septiembre), Tlaxcala (octubre) e Hidalgo (enero de 1990) para elegir a los Congresos estatales, y en distintas fechas, que van de julio de 1989 a marzo de 1990 se renovarán Congresos y municipios en Chihuahua, Durango, Oaxaca, Aguascalientes, Sinaloa, Puebla, Tamaulipas, Guerrero, Baja California Sur y Quintana Roo. Por último, en diciembre de 1989 se llevaron a cabo elecciones municipales en Michoacán.

En consonancia con los niveles de competencia alcanzados en la elección federal de 1988, se esperaban cerradas contiendas en Chihuahua, Michoacán y Baja California. Tal pronóstico acertó tan sólo parcialmente. Acción Nacional su-

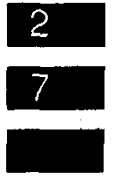




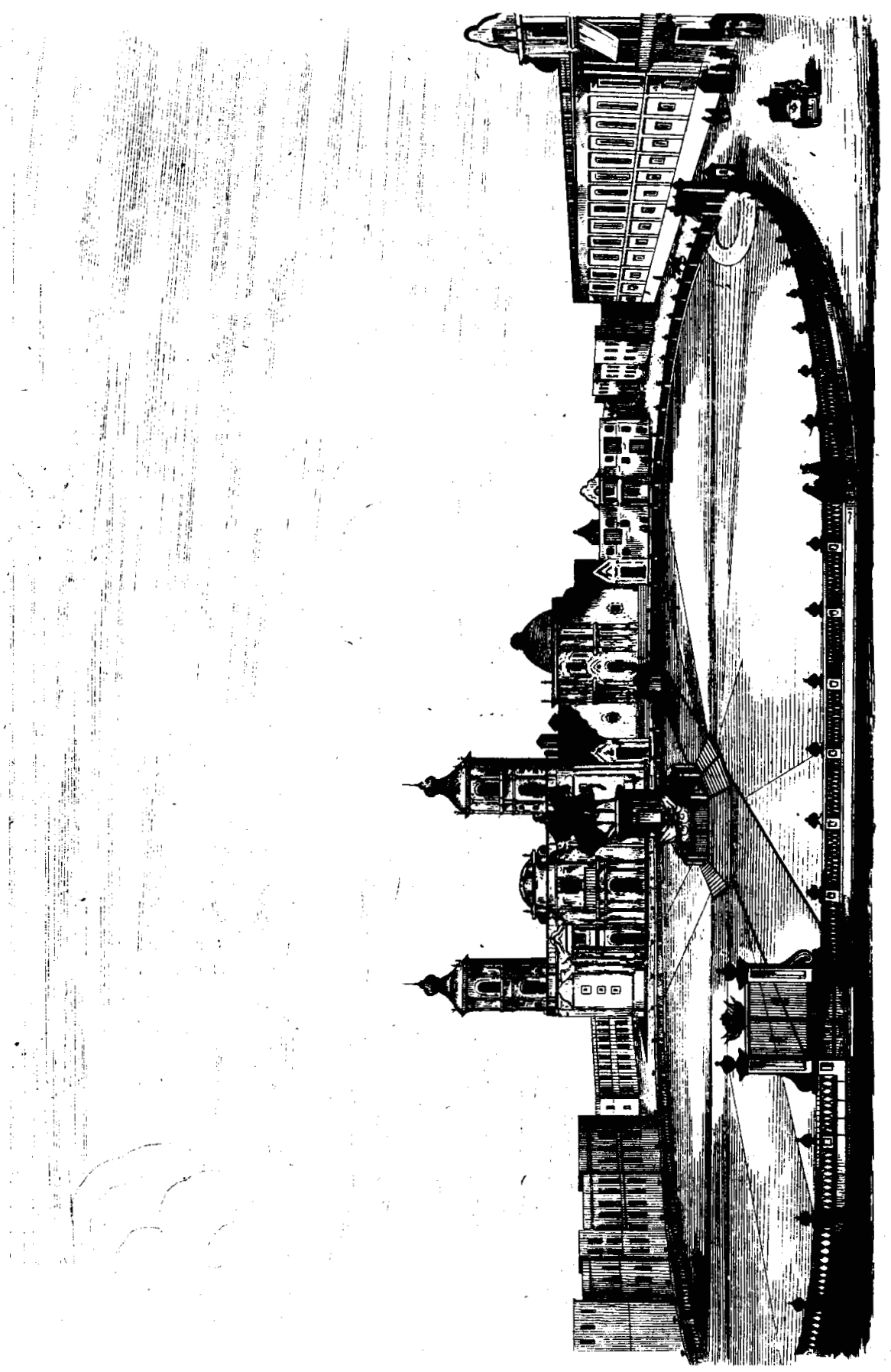


frió en Chihuahua un serio revés, al tiempo que en Baja California logró lo que ningún partido opositor había logrado en la historia posrevolucionaria de México: el reconocimiento de su triunfo en una elección de gobernador.

Michoacán ocasionó gran polémica. La elección de Congreso local fue el marco para enfrentamientos entre el PRI y el recientemente constituido Partido de la Revolución Democrática, el cual alegó fraude generalizado y promovió la conformación del Tribunal Independiente Ciudadano, que dictaminó el triunfo del PRD. Lo cierto es que si el PRI no lograba mayoría en la Cámara de Diputados, ponía en riesgo la gubernatura en virtud de que el Congreso está facultado para cambiar al gobernador; en consecuencia, resulta probable que haya echado mano de prácticas fraudulentas para mantener a toda costa su mayoría en la Cámara de Diputados local.

Las elecciones municipales en ese mismo estado (en diciembre de 1989) presentaron un perfil distinto. Se reconoció el triunfo del PRD en la capital y en las más importantes ciudades. Las cifras ofrecen una suerte de empate, pues oficialmente al PRI le correspondieron 58 alcaldías y al PRD 46, quedando 31 municipios en conflicto. Lo cierto es que el PRD aparece como la fuerza mayoritaria por la relevancia política de las localidades que ganó. La violencia, en julio como en diciembre, fue parte del conflicto político detonado por los resultados electorales. A las tomas de palacios municipales y a la instalación de ayuntamientos paralelos los perdedores respondieron con hostigamiento y asesinatos de militantes perredistas.

La violencia poselectoral también asomó en Guerrero. Esta entidad, que no presentó elevados niveles de competitividad en la elección federal de 1988, sí los registró en las locales de diciembre de 1989. El PRD apareció como el principal contendiente del PRI al lograr nueve triunfos municipales, e instaló ayuntamientos paralelos en otros 20. El conflicto alcanzó niveles tales, que hizo necesaria la intervención directa de las autoridades federales. Una comisión negociadora de ambos partidos se instaló en la Sécretaría de Gobernación con el fin de buscar soluciones. Por vez primera en el sexenio, la autoridad federal se vio obligada a intervenir en conflictos electorales de carácter local, con lo cual se sentó un precedente.

Un hecho que llama significativamente la atención es el elevado nivel de abstención que se ha presentado en el conjunto de los procesos locales. Tal fenómeno aparece en entidades en las que la competitividad no se ha apartado de los patrones prevalecientes con anterioridad a julio de 1988 , así como en las que surje como ingrediente novedoso. Falta aún realizar estudios detallados al respecto. El hecho de que grandes conjuntos de la población se alejen de las contiendas comiciales, independientemente de los niveles de competitividad que registren, puede tener consecuencias políticas aún desconocidas.

\section{LA REFORMA ELECTORAL: ¿UN ATENUANTE?}

Otro ámbito fuertemente impactado por la elevada competitividad electoral de 1988 es el de la legislación comicial. La huelga de hambre del candidato presidencial panista; la convocatoria de Salinas de Gortari a revisar los ordenamientos en la materia; la consulta pública efectuada por la Comisión Federal Electoral y la Cámara de Diputados; el periodo extraordinario de sesiones del Congreso y las modificaciones a los artículos constitucionales relativos, han sido los 


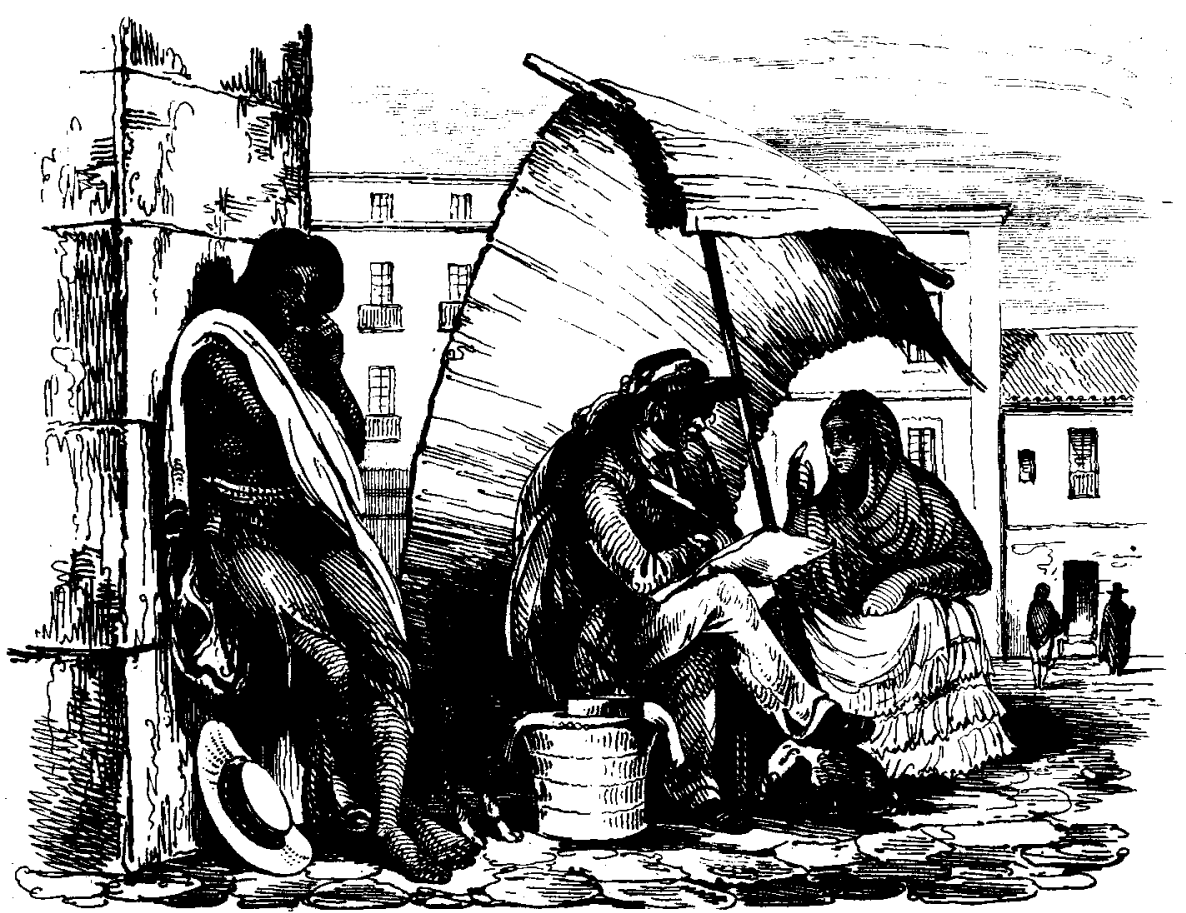

peldaños de este proceso. Falta aún que las Cámaras -en su próximo periodo ordinario de sesiones- reformen o deroguen el actual Código Federal Electoral y den paso a la nueva ley.

Resulta evidente que de no haberse llegado a los actuales niveles de competitividad, no hubiera sido necesario renovar las reglas de la competencia político-electoral. Al parecer, ningún actor político quedó satisfecho con el desenlace del conflicto motivado en julio de 1988 por el inusitado incremento de la competitividad. Los órganos del Estado y el conjunto de los partidos políticos prơmovieron de inmediato la reforma electoral.

Tal proceso -que, por cierto, no resulta novedoso en nuestro país- se vio impactado por las consecuencias de la nueva situación política; ello es así, particularmente, en el caso de la Cámara de
Diputados. La elección más competida de nuestro tiempo derivó en una composición de ese órgano, que no permite realizar reformas constitucionales con el solo voto del partido oficial ni con el del conjunto de los diputados de la oposición. La Constitución sólo puede ser modificada con el voto de las dos terceras partes de la Cámara (artículo 135). Ni el PRI, ni el conjunto de la oposición reúnen los 334 votos requeridos para tal fin, lo que obliga a los partidos políticos a entablar complejas negociaciones.

Las diferencias de opinión de las diversas fuerzas se dejaron sentir tan pronto se iniciaron las consultas. Las propuestas presentadas apuntaban hacia rumbos distintos. La Comisión Especial para la Consulta Pública sobre Reforma Electoral y la Concertación entre los Partidos Políticos Nacionales de la Comisión Federal Electoral (ese era su kilo- 
métrico nombre) no logró su objetivo: presentar un proyecto de reformas que satisfaciera a todos los partidos. Debido a ello y por vez primera en la historia del reformismo electoral mexicano, el ejecutivo federal se abstuvo de enviar al Congreso su iniciativa en la materia. Los partidos políticos presentaron sus propuestas.

El debate se centró en la conformación y facultades de los organismos responsables de preparar, vigilar y calificar las elecciones. De acuerdo con la opinión generalizada, de la credibilidad de estos órganos depende la legitimidad de los resultados comiciales. Las bancadas del PAN, PRD y PARM establecieron criterios mínimos de imparcialidad para tales órganos. A pesar de ello, el PAN decidió, en el último momento, llegar a un "acuerdo de caballeros" con la diputación priista, lo que permitió reformar siete artículos constitucionales. Sigue abierto el debate en torno a la composición de los órganos electorales. La reforma constitucional establece formas y procedimientos inéditos para su conformación y para la designación de sus integrantes. Falta aún la definición de sus facultades y otras cuestiones de detalle, por lo que resulta prematuro intentar ahora una evaluación final.

Las consecuencias de los nuevos niveles de competitividad se reflejan, de manera mucho más clara, en las disposiciones constitucionales relativas a la conformación de la Cámara de Diputados, recientemente aprobadas. La nueva redacción del artículo 54 establece lo que se suele llamar "cláusula de gobernabilidad" que, en realidad, no es más que una medida de seguridad del régimen ante la eventualidad de que la competitividad electoral persista. El mencionado artículo establece reglas para hacer la distribución de las 200 curules de dicha Cá- mara, por el principio de representación proporcional. Determina, en primer lugar, que para que los partidos tengan derecho a registrar listas de candidatos a diputados plurinominales, deberán acreditar previamente la candidatura de diputados por mayoría relativa en, cuando menos, 200 de los 300 distritos uninominales. Para participar en la distribución de curules proporcionales, los partidos deberán alcanzar una votación nacional mínima de $1.5 \%$. El artículo 54 hace referencia, asimismo, a tres situaciones límite: $a$ ) ningún partido podrá contar con más de 350 diputados (70\% del total), aun cuando su porcentaje de votos sea superior; de darse el caso, al partido en cuestión se le asignará un determinado número de diputados de representación proporcional, a fin de que éstos, adicionados a los electos por mayoría relativa, sumen $350 ; b$ ) si ningún partido obtiene más de $35 \%$ de los votos, a los que hayan cumplido con los requisitos estipulados, se les distribuirán curules proporcionales hasta que la suma de diputados electos por ambos principios corresponda a un porcentaje similar al de votos obtenidos; $c$ ) al partido que tenga mayor nümero de diputaciones de mayoría y cuando menos $35 \%$ de la votación total, se le asignará el número de diputaciones proporcionales que le permita obtener la mayoría absoluta de la Cámara; adicionalmente, se le otorgarán otros dos diputados por cada punto porcentual en que rebase 35 por ciento.

Evidentemente, semejante disposición está destinada a asegurarle al partido gubernamental la mayoría legislativa, pues es el que cuenta con la mejor distribución regional de sus triunfos distritales. Si se aplican las nuevas disposiciones a los datos oficiales obtenidos de la contienda de 1988, tal intención queda 


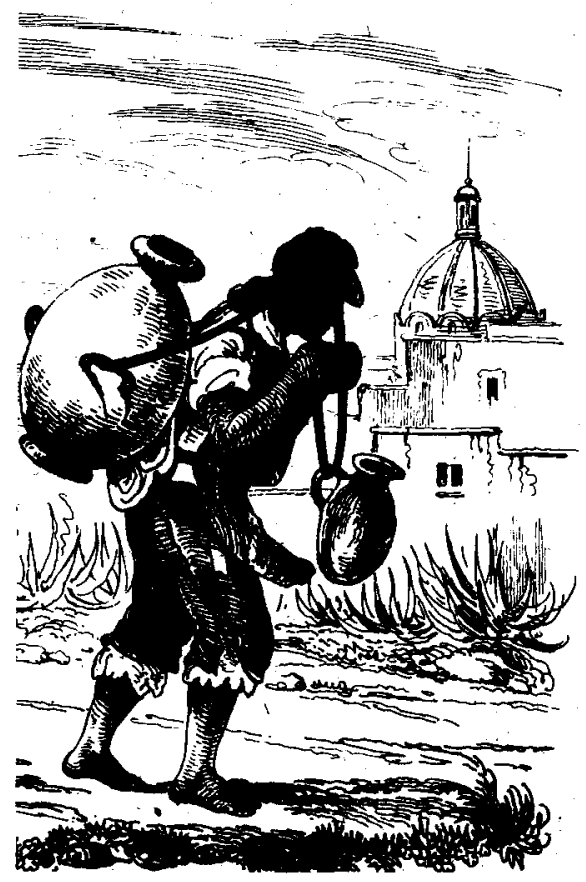

en evidencia. El PRI logró $51.11 \%$ de la votación y alcanzó 237 victorias de mayoría, de tal manera que le corresponderian catorce diputados de representación proporcional para alcanzar mayoría absoluta, más otros 32 electos por ese mismo principio, dado que su porcentaje de votos excede en 16 puntos el mínimo de 35\%. Asi, en lugar de las 260 curules con las que cuenta actualmente, alcanzaría 273 y una mayoría más cómoda que la actual.

\section{LA CONFORMACION DE LOS PARTIDOS}

Los nuevos perfiles de la competitividad electoral han impactado también la vida interna de los partidos políticos. Todos ellos -casi sin excepción-preparan su inserción en el nuevo panorama político. Me referiré a lo que ha sucedido con las tres fuerzas con mayor peso electoral. El PRI -todavía mayoritario- escuchó de voz de su candidato presidencial una sentencia significativa. Al anunciar su triunfo, Salinas de Gortari afirmó que había llegado a su fin la etapa del partido "prácticamente único". Tal aseveración tuvo repercusiones instantáneas en los niveles directivos del PRI. El senador Humberto Lugo Gil renunció a la secretaría general el 2 de agosto y fue reemplazado por Manuel Camacho Solís, uno de los hombres más cercanos a Salinas.

En su primer discurso en tal cargo, Camacho planteó la necesidad de constituir nuevas formas de relación entre gobierno, sociedad y partidos políticos. El mensaje admitía implícitamente la necesaria renovación del PRI y la modificación de uno de sus rasgos centrales: su relación con el gobierno. A partir de ese momento, el PRI ha pretendido presentarse como "partido en el gobierno" y no como "partido del gobierno".

No tardó en surgir la Corriente Crítica del PRI. El 7 de agosto de 1988, el veterano político Rodolfo González Guevara sentenció: "cambia el PRI o pierde el poder". De manera inusitada el PRI reconoció a principios de noviembre la existencia formal del grupo encabezado por González Guevara, al cual le ha dado un tratamiento distinto al que recibió la Corriente Democrática unos meses antes. Si bien es relativamente débil, la Corriente Crítica constituye un elemento relevante: mantiene una actitud de crítica permanente -reconoció incluso el triunfo perredista en las elecciones legislativas en Michoacán y su principal dirigente formó parte del Tribunal Independiente Ciudadano- y ha sido tolerada; sus miembros, aunque sin gran éxito, participan en la vida interna del partido y han ganado algunos espacios en su estructura. 
Los sectores priistas responden de diversas maneras a los llamados modernizadores de la dirección. El más activo ha sido el popular. El Consejo Nacional de la Confederación Nacional de Organizaciones Populares (CNOP), realizado a fines de febrero de 1990 , acordó impulsar la conformación de cinco movimientos: sindical (trabajadores al servicio del Estado); gremial (comerciantes, locatarios, taxistas, etc.); urbano-popular (coloncs e inquilinos); de técnicos y profesionistas, y de ciudadanos, en el cual se plantea agrupar a organizaciones ecologistas, femeniles, juveniles, etcétera.

El proyecto cenopista impulsa estructuras novedosas que -se dice- son modelo de las que habrán de conformar al partido gubernamental en su "cuarta etapa". Supuestamente, esos movimientos no reemplazarán en lo inmediato al sector popular, aun cuando se busca ya un nuevo nombre y emblema para el organismo. Es posible que, para cuando se realice la próxima Asamblea Nacional priísta (segundo semestre de 1990), tales modificaciones se encuentren en pleno desarrollo. De cualquier manera, resulta clara la intención de encuadrar en el PRI a nuevos sectores y grupos sociales que no han encontrado cabida en su tradicional estructura corporativa; con ello se pretende disputar a la oposición su creciente clientela electoral.

Algunos dirigentes del PRI han planteado la posibilidad de cambiar el nombre del partido, lo que presuntamente sucederá al iniciar su cuarta etapa. ${ }^{4} \mathrm{De}$ ser así, es posible que también se transformen de manera significativa sus estatutos. Al respecto, se han hecho reiteradas declaraciones sobre el renovado

${ }^{4}$ Las tres anteriores han sido: PNR, de 1929 a 1938; PRM, de 1938 a 1946, y PRI, de 1946 a 1990.
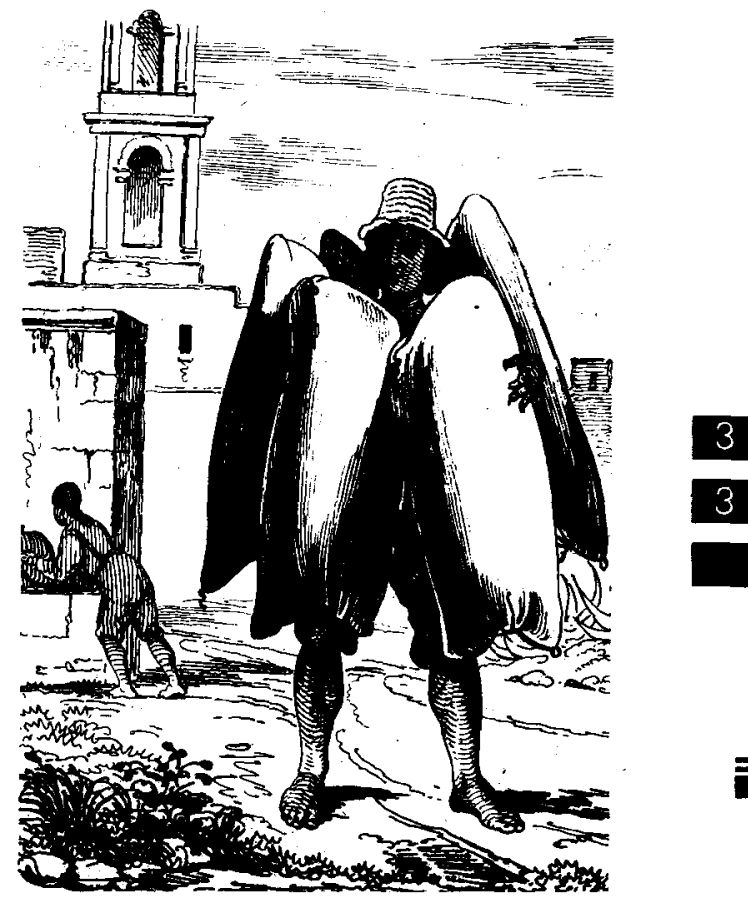

3

papel que jugará la estructura territorial. Al parecer, se pretende otorgar mayor importancia y facultades a los comités de las zonas donde los electores viven y votan, con la intención de fortalecer la presencia partidaria entre la ciudadanía, en sustitución del corporativismo que tradicionalmente ha sustentado a ese partido.

Por lo que hasta ahora se puede observar, la ruta de la renovación del PRI está enfocada hacia la disputa electoral en los nuevos marcos de competitividad; su cuarta etapa, al parecer, estará destinada a disputarle a los partidos opositores los espacios sociales en los cuales su presencia es mayor.

Las dos principales fuerzas opositoras se encuentran, aparentemente, más preocupadas por consolidar lo avanzado. Acción Nacional se ha mostrado especialmente activo en materia de re- 


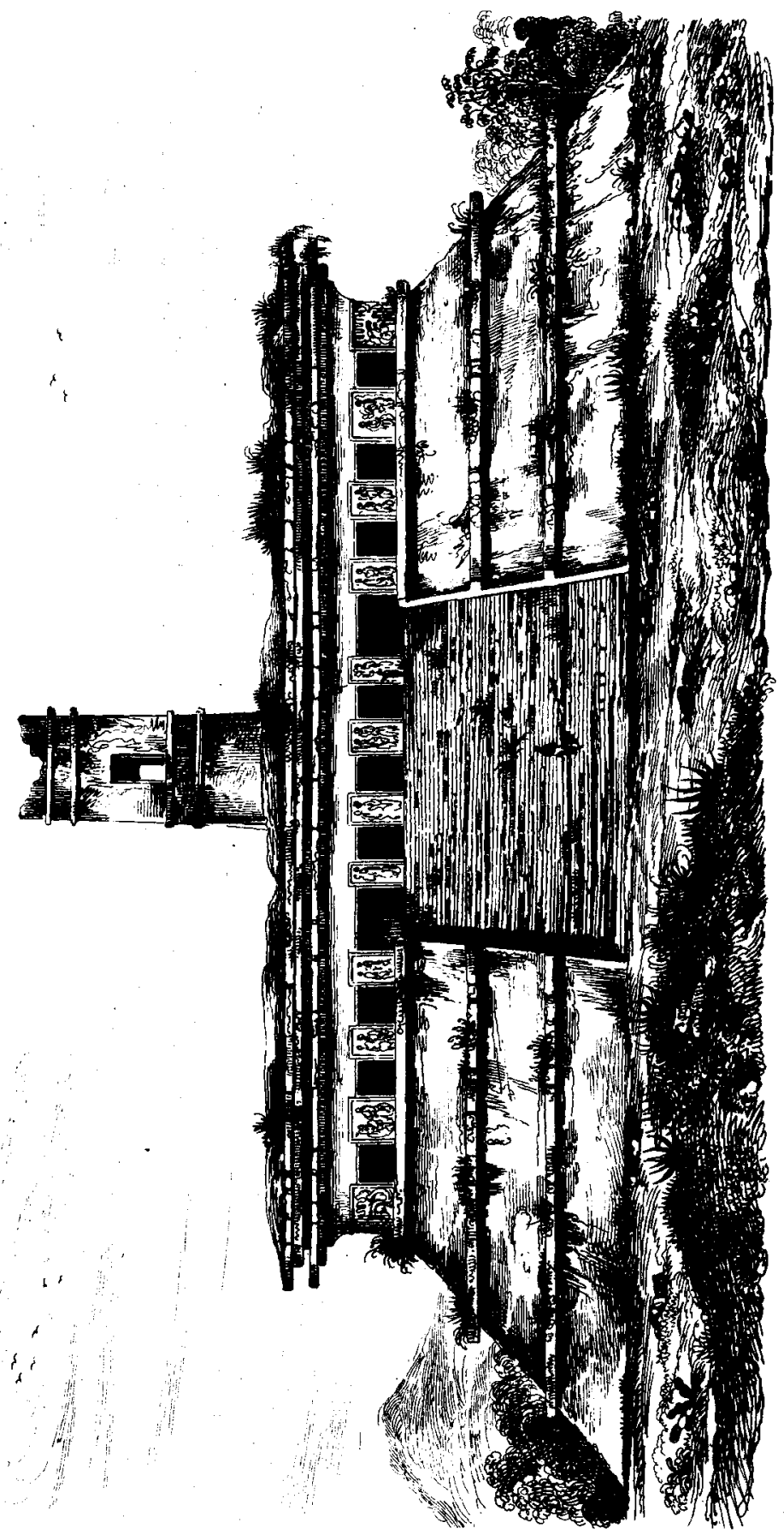


forma electoral. El 2 de diciembre de 1988 , tan pronto como Salinas asumió la presidencia, se reunió con la dirección panista y llegaron al acuerdo de que gobierno y partidos estudiarían la posibilidad de realizar reformas a la legislación electoral. El 26 de diciembre -durante el primer periodo ordinario de sesiones del Congreso- los diputados del PAN presentaron ocho iniciativas relativas a ese ordenamiento. Previo al inicio del periodo extraordinario convocado para tal fin, la bancada panista era la única que contaba con un proyecto de código electoral completo y alternativo; presentó además iniciativas de reformas a todos los artículos constitucionales en la materia.

El entusiasmo del PAN por el reformismo electoral se vio complementado por otro hecho excepcional (cuando menos, en nuestro medio político). Sus reuniones publicitadas con Salinas se volvieron frecuentes y sus canales de comunicación con el gobiemo se ampliaron y funcionaron con eficiencia. La comunicación llegó a ser tan intensa que, en vísperas de la aprobación de los cambios a la Constitución en materia electoral, se habló de acuerdos entre el PAN y el presidente. Los panistas dieron a conocer la existencia de una "carta de intención", en la que se establecían los principales elementos de la reforma a la legislación secundaria que, según el PAN, había sido negociada y acordada con Salinas gracias a los buenos oficios de la Secretaría de Gobernación.

Las revelaciones provocaron estupor dentro del propio PaN. Ese partido, tradicionalmente reacio a llegar a compromisos públicos con el gubernamental,modificó de pronto su actitud. La dirección panista habló de cambios en el perfil del partido: al haber conquistado una gubernatura y más de 100 de los 500 diputados federales, el PaN pasaba de la oposición a la coparticipación en el poder. Un diputado panista llegó a decir que la reforma electoral pactada era una especie de "aterrizaje planeado" mediante el cual el PRI se preparaba para abandonar el poder de manera pacífica y ordenada.

Semejantes posiciones fueron duramente cuestionadas por prominentes miembros del blanquiazul. La confrontación se expresó en ocasión de la elección de su nueva directiva, llevada a cabo a fines de febrero de 1990 . Un grupo de sus más importantes dirigentes impulsó la candidatura de Gabriel Jiménez Remus, en oposición a la reelección de Luis H. Álvarez. Desde su postulación, Jiménez Remus pidió mayor cautela en las relaciones del PAN con el gobierno, criticando implícitamente los cambios introducidos por Álvarez. La contienda interna fue la más reñida en la historia reciente del PAN y marcó con nitidez la línea de separación entre las dos posiciones. Incluso se llegó a hablar de la existencia de una "corriente crítica" en su interior, aun cuando en este caso tal tendencia cuenta con más de un tercio de los miembros del Consejo Nacional blanquiazul.

Al parecer, la controversia gira en torno al nuevo carácter del partido. La inédita competitividad entre tres fuerzas políticas coloca al PAN frente a la necesidad de consolidar sus avances. La dirección triunfante propone nuevas formas de participaciôn en las labores de gobierno, mientras que la corriente opositora expresa sus reservas respecto de tal estrategia y considera que ese partido debe conservar su carácter marcadamente opositor. Las próximas elecciones federales pondrán a prueba la diferenciación interna del PAN, así como los resultados de las tácticas impulsadas por ambas corrientes. 
En el caso de la tercera fuerza electoral, su ruta, tras los comicios de 1988, ha resultado más compleja. El 14 de septiembre de ese año, Cárdenas convocó a construir el partido "que nació el 6 de julio". Las fuerzas que integraron el FDN y apoyaron la candidatura cardenista se deslindaron de tal proceso. Únicamente el PMS -que poco antes de los comicios retiró su candidatura y se sumó a la de Cárdenas- se incorporó al nuevo proyecto. La Corriente Democrática (conformada por ex priistas), el pMS y otras agrupaciones se abocaron al cumplimiento de los requisitos (afiliación, celebración de asambleas, etc.) para la constitución y obtención del registro legal del nuevo partido.

El Partido de la Revolución Democrática realizó su asamblea nacional constitutiva y acordó comunicar a la Comisión Federal Electoral el cambio de denominación del PMS, en lugar de proseguir con los trámites de registro del nuevo partido. La inminencia de procesos electorales locales, fundamentalmente en Michoacán, los llevó a optar por un trámite rápido: cambiar el nombre de un partido registrado, y no esperar el dictamen sobre el registro de uno nuevo. El PRD afirmó haber cubierto los requisitos para la obtención de su registro; lo cierto es que nunca lo demostró y al menos quedó la duda de que así fuera. De no haberse logrado tal objetivo (65 000 afiliados, distribuidos en las dos terceras partes de las entidades federativas) quedaría claro que sólo una fracción muy pequeña del amplio electorado cardenista estuvo dispuesta a conformar el partido de esa corriente política.

De las tres principales fuerzas políticas, el PRD es la que más dificultades ha enfrentado debido al agitado calendario de elecciones locales. En parte, ello puede deberse a su reciente conformación, aunque también es cierto que en su interior existen posiciones diversas, lo que ha provocado disputas por los cargos de dirección. En el VI Pleno de su Consejo Nacional, celebrado el 24 de febrero de 1990, Cárdenas sostuvo que aún subsisten los grupos que originalmente conformaron al PRD y que a ello se deben la desconfianza, el sectarismo y la exclusión. Parece ser que buena parte de las energías de ese partido se han volcado hacia su interior, en búsqueda de una unidad política que aún no consigue, a pesar de que sus logros en las elecciones locales no son del todo despreciables. Es posible que su clientela electoral se esté nutriendo de los ciudadanos que en julio de 1988 votaron por los partidos que. conformaron el FDN.

Los restantes partidos políticos -los que originalmente dieron vida al FDNhan vuelto a la marginalidad. En las elecciones locales posteriores al verano de 1988 no han alcanzado, ni remotamente, los niveles de votación que obtuvieron entonces. El beneficio que les brindó su apoyo a la candidatura presidencial de Cárdenas, fue pasajero. El PFCRN no sólo ha vuelto a su vieja política de alianzas con el gobierno, sino que se ha prestado y sumado, en diversos foros, a la campaña de hostigamiento contra el PRD. LOS beneficios que hasta el presente le ha reportado tal actitud no están a la vista, pero sí su mayor descrédito.

\section{CONCLUSIÓN}

¿Habrá sido pasajero el elevado nivel de competitividad alcanzado en las elecciones federales de 1988? Al parecer no es así. Todo indica que algunas zonas del país se perfilan hacia una intensa competitividad, con la participación de dos y hasta tres fuerzas con importante pre- 
sencia político-electoral. Las elecciones de Baja California, Michoacán y Guerrero sirven para ilustrar tal opinión. En otras entidades, aun cuando no se han repetido los niveles de competencia registrados en 1988, los triunfos de la oposición han sido superiores a los que esos partidos alcanzaban en el pasado. Las elecciones locales en el Estado de México, a realizarse en noviembre de 1990 , y las federales de diputados y senadores (septiembre de 1991) mostrarán qué tanto se consolida la nueva situación de competencia en el país.

Los comicios de 1991 serán la primera prueba para la nueva legislación electoral. Se pondrán en práctica las modifi- caciones constitucionales y ya para entonces estará vigente la nueva ley secundaria. La renovada composición del órgano encargado de las elecciones, le ofrece al régimen la posibilidad de legitimar los resultados, hacerlos creibles para el conjunto de la población y aceptados por los partidos contendientes. También se pondrá a prueba el mecanismo ideado para mantener la mayoría gubernamental en el Congreso. Para las elecciones de la mitad del Senado, al parecer el PRI -o el partido en que se transforme- no tendrá grandes problemas; quizá vuelva a perder en el Distrito Federal y en Michoacán. En Baja California, Estado de México, Morelos y Guerrero tampoco es

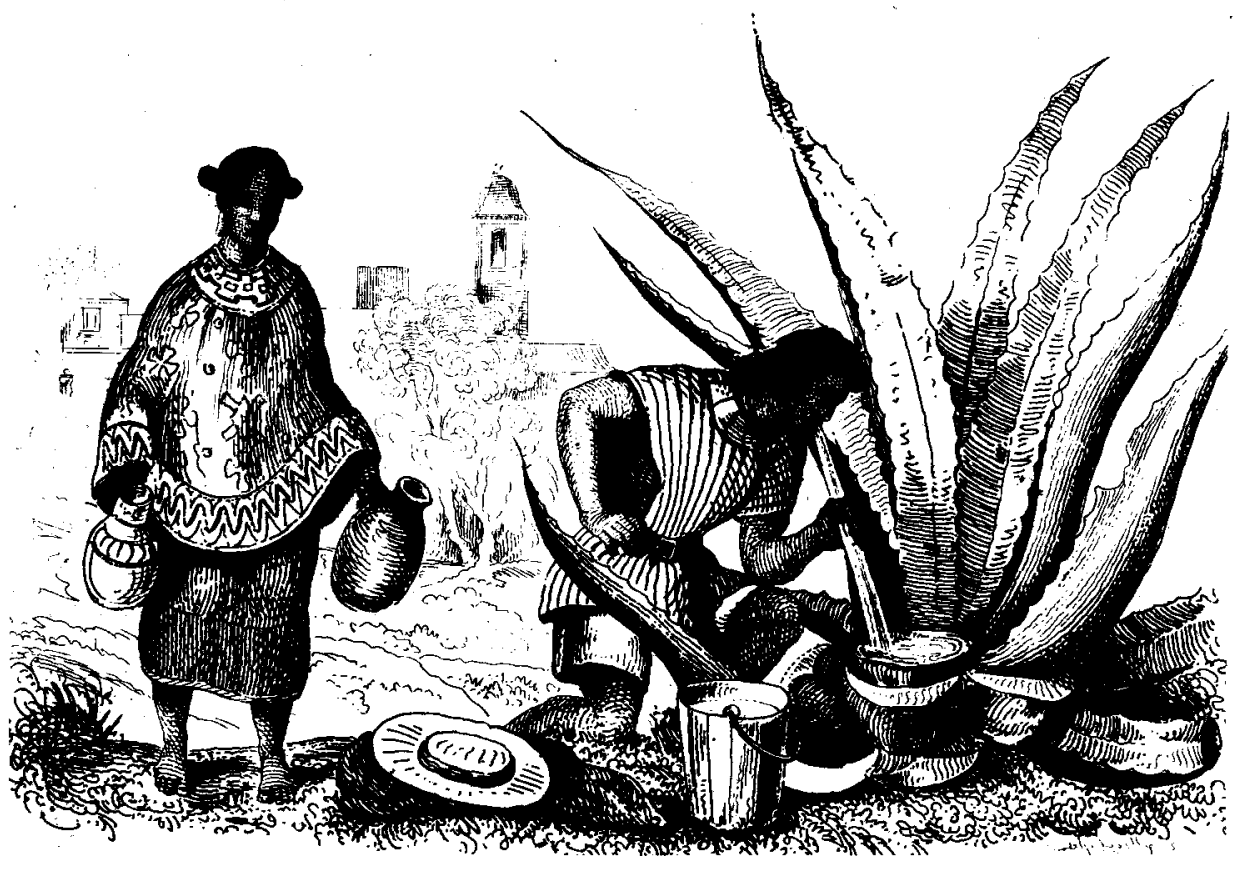


remota la posibilidad de triunfos opositores.

La elección de diputados puede hacerse más reñida. Si llegara a serlo, el régimen cuenta con la redacción reformada del artículo 54 constitucional para ganar la mayoría en ese organismo, aun cuando con ello ponga en riesgo la legitimidad de la elección de esa Cámara, y de las instituciones políticas en su conjunto. $\mathrm{Si}$, además, los altos niveles de abstención persisten, es posible que tal deslegitimación tenga importantes consecuencias políticas. La abstención no es tan sólo rechazo al PRI, como en algún momento se pensó; es rechazo al resto de las opciones y a la participación política en su sentido más general.

Los partidos enfrentarán un importante reto en 1991. Para encararlo, el PRI se prepara en forma acelerada. El énfasis en la nueva estructura territorial le puede producir ventajas. Sin embargo, es dudoso que logre penetrar con éxito en los sectores sociales que se han manifestado electoralmente por la oposición. La conformación de movimientos que reemplacen a los viejos sectores priístas aparece como una decisión cupular que dificilmente puede estar sustentada en las bases sociales necesarias para realizar un proyecto de tal dimensión. Además, es posible que afloren conflictos al interior y entre los sectores que se encuentran rezagados de la "renovación" partidista. Los intereses de las viejas estructuras corporativas, según parece, no tienen lugar en el diseño del nuevo PRI, lo que puede causarle nuevas e importantes fracturas. Finalmente, es dificil saber cuáles serán los mecanismos para que el éxito alcanzado por la agresiva campaña del presidente Salinas en busca del consenso no obtenido en julio de 1988, pueda transmitirse a su partido.

Acción Nacional se encuentra ante el reto de curar las heridas que le causó la elección interna más reñida de su historia reciente. Se enfrenta, además, al nada fácil problema de definir con mayor claridad el tipo de relaciones que está dispuesto a sostener con el gobiemo. De la "oposición leal" pasó a la impaciencia electoral pero, al parecer, ahora retorna a la lealtad. De la forma en que sus dirigentes entiendan la nueva etapa que vive ese partido, depende en buena medida su unidad. Se habla ahora de la existencia de una corriente crítica en su interior, y por la dimensión y trayectoria de algunos de los dirigentes que quedan incluidos en esa posición, es posible suponer implicaciones nada favorables para ese partido. Su oportunidad para consolidar lo avanzado e, incluso, avanzar en el terreno de su presencia electoral, se dará en función de la capacidad que demuestre para recomponer su situación interna.

El PRD enfrenta una situación similar a la del PAN, pero en condiciones de mayor fragmentación. Requiere unidad de acción y la construcción de sus propias instancias de organización y decisión. El primer Congreso Nacional de ese partido, programado originalmente para el segundo semestre de 1990, será buena ocasión para evaluar sus avances. En ese evento, se elegirá además a la dirección permanente de la organización, lo cual mostrará qué tanto se ha consolidado como estructura política unitaria de las corrientes que lo conformaron. De todo ello dependerá su éxito o fracaso en.la elección federal de 1991, la primera de ese carácter en la que participará como partido.

La abstención continúa representando una amenaza para todas las fuerzas políticas e incluso para posibilitar el proceso de democratización que, de una u otra manera, estamos viviendo. 